\title{
Rickettsiosis, una enfermedad letal emergente y re-emergente en Colombia
}

\author{
Juan Carlos Quintero Vélez ${ }^{1}$, Marylin Hidalgo ${ }^{2 *}$, Juan David Rodas González ${ }^{1}$ \\ ${ }^{1}$ Grupo de investigación Centauro, Facultad de Ciencias Agrarias, Universidad de Antioquia. Colombia. \\ ${ }^{2}$ Grupo de Enfermedades Infecciosas, Departamento de Microbiología. Facultad de Ciencias. \\ Pontificia Universidad Javeriana. Bogotá, D.C. Colombia. \\ * hidalgo.m@javeriana.edu.co
}

Recibido: 11-11-2011; Aceptado: 27-01-2012

\begin{abstract}
Resumen
La rickettsiosis fueron inicialmente descritas en Colombia en 1937 por el Doctor Luis Patiño debido a un brote de una enfermedad con signos inespecíficos. El género Rickettsia esta constituido por bacterias intracelulares obligadas gram negativas que han causado varias epidemias a nivel mundial y son transmitidas principalmente por garrapatas, pulgas, piojos o ácaros. La más letal de estas enfermedades febriles se conoce como la Fiebre manchada de las montañas rocosas que es causada por la Rickettsia rickettsii, pero además existen el tifus endémico causado por la Rickettsia typhi y el tifus epidémico causado por Rickettsia prowazekii. En Colombia en los últimos años se han presentado varios brotes de rickettsiosis de la fiebres manchadas, entre los que se destacan los ocurridos en los municipios de Necoclí y Turbo ambos en el departamento de Antioquia en los años 2006 y 2008 respectivamente, y un tercero en el municipio de los Córdobas del departamento de Córdoba en el 2007. El objetivo de esta revisión es dar a conocer el estado del arte de la rickettsiosis, enfermedad letal y olvidada en nuestro medio, así como el planteamiento de preguntas motivo de preocupación para investigaciones futuras que permitan tener un mejor entendimiento de ésta entidad potencialmente endémica en algunas zonas de Colombia.
\end{abstract}

Palabras clave: brote, emergentes, reservorio, rickettsiosis, vector, tifus, zoonosis.

\begin{abstract}
Rickettsiosis: a deadly emerging and re-emerging disease in Colombia. Rickettsiosis was first described in Colombia in 1937 by Dr Luis Patiño during an outbreak of a disease with unspecific signs. Rickettsia is a genus of Gram-negative intracellular obligatory bacteria having caused several epidemics around the world, and are transmitted mainly by ticks, fleas, lice and mites. The most fatal within this group of diseases is known as Rocky Mountain Spotted Fever (RMSF), which is caused by Rickettsia rickettsia. There is also the endemic typhus caused by Rickettsia typhi and epidemic typhus caused by Rickettsia prowazekii. In Colombia, several outbreaks of RMSF have occurred during the last decade. The best known among those have hit the municipalities of Necoclí and Turbo, in Antioquia in 2006 and 2008 respectively, and Los Cordobas in the department of Cordoba in 2007. The goal of this review is to describe the state of the art of rickettsiosis, a forgotten lethal disease that has re-emerged in our country, and leave some questions as an inspiration for future research that will hopefully lead scientists to a better understanding of this entity potentially endemic in some areas of Colombia.
\end{abstract}

Key words: outbreak, emerging, reservoir, rickettsiosis, vector, typhus, zoonoses.

\section{Resumo}

Rickettsioses, uma doença mortal emergente e re-emergente na Colômbia. A rickettsiose na Colômbia foi descrita pela primeira vez em 1937 pelo Dr. Luis Patiño devido a um surto de uma doença com sinais inespecíficos. O gênero Rickettsia é constituído por bactérias intracelulares obrigatórias gram-negativas que têm causado várias epidemias em todo o mundo e são transmitidas principalmente 
por carrapatos, pulgas, piolhos ou ácaros. A mais mortífera destas doenças febris é conhecida como a Febre Maculosa das Montanhas Rochosas que é causada por Rickettsia rickettsii, mas há também o tifo endêmico causado pela Rickettsia typhi e o tifo epidêmico causado por Rickettsia prowazekii. Na Colômbia nos últimos anos tem havido vários surtos de rickettsioses do grupo das febres maculosas; destaques ocorreram nos municípios de Necocli e Turbo, no departamento de Antioquia em 2006 e 2008, respectivamente, e um terceiro no município dos Cordobas no departamento de Córdoba, em 2007. O objetivo desta revisão é apresentar o estado da arte da rickettsiose, doença letal e esquecida em nosso meio, bem como fazer perguntas de interesse para futuras pesquisas para permitir uma melhor compreensão desta entidade potencialmente endêmica em algumas áreas da Colômbia.

Palavras-chave: surto, emergentes, reservatório, rickettsiose, vetor, tifo, zoonose.

\section{Introducción}

Las rickettsias son un género de bacterias intracelulares obligadas trasmitidas por artrópodos hematófagos como las garrapatas, piojos, pulgas y ácaros (1). Este género bacteriano se divide en cuatro grandes grupos, el grupo Tifus, el grupo de las Fiebres Manchadas, el grupo Transicional y el grupo Ancestral. Todos ellos albergan especies que representan patógenos potenciales de importancia para el humano (2).

En las últimas décadas, las rickettsiosis humanas han despertado gran interés en algunos países de América como Brasil y Perú por su carácter re-emergente (3-5), en otros como Colombia por la presentación de casos fatales y de brotes de alta letalidad (6-9); mientras que en otros como Estados Unidos (EU), han permanecido como enfermedades endémicas de presentación estacional, asociadas a la aparición de sus vectores, o condicionadas por cambios ecológicos. Debido al incremento notable en la presentación de casos humanos en algunas áreas y al interés despertado en estas bacterias como potenciales armas de bioterrorismo, se han desarrollado centros de referencia para su diagnóstico tanto en Norte como en Sur América, ubicados principalmente en EU (Centro de Control y Prevención de Enfermedades o CDC por Center for Disease Control de Atlanta y el Centro de Enfermedades Tropicales de la Universidad de Texas o UTMB por University of Texas Medical Branch en Galveston Texas) y Brasil (Departamento de Medicina Veterinaria preventiva y Salud Animal de la Universidad de Sao Paulo).

Esta revisión pretende llevar cabo una descripción general de las rickettsiosis para tener un mejor entendimiento de esta enfermedad letal emergente y re-emergente en diferentes sitios geográficos del mundo, además deja planteadas algunas preguntas de investigación para Colombia y renueva el interés sobre éstas importantes zoonosis por su riesgo potencial para la salud pública.

\section{Historia}

Historia de las fiebres manchadas de las montañas rocosas En 1899 se reconoció por primera vez la Fiebre Manchada de las Montañas Rocosas (o RMSF por Rocky Mountain Spotted Fever), por Maxey, en Norte América (10), pero los pioneros en investigar la etiología de la RMSF, fueron los patólogos Wilson y Chowning en 1902 (11), quienes estudiaron la enfermedad a partir de necropsias de individuos infectados y la describieron como una falla en los capilares sanguíneos asociada a infección con parásitos intra-eritrocitarios (Pyroplasma hominis) (11-13). En 1906, estudios realizados por Howard Ricketts en curíes o cobayos, demostraron que la RMSF era transmitida a través de sangre infectada, que el vector de esta enfermedad eran las garrapatas de la especie Dermacentor andersoni y que este vector transmitía la bacteria a través de su progenie (transmisión transovarial) $(14,15)$. Luego de esto, en los Estados Unidos, América Central y Sur América, los médicos comenzaron a identificar casos de RMSF transmitida por garrapatas. La descripción clínica de la enfermedad se realizó en 1925 a partir de un niño de Indiana (Estados Unidos), que sufrió la enfermedad y luego se confirmó con hallazgos de laboratorio $(16,17)$.

En 1931, Badger et al, describieron casos de RMSF en diferentes partes de Estados Unidos y confirmaron que la enfermedad estaba generalizada en Norte América (18, 19). En Suramérica específicamente en Brasil, desde 1930 se ha documentado la enfermedad y se le denominó "Tifus exantémico de Sao Pablo", "Tifus exantémico de Minas Gerais" y finalmente "Fiebre manchada del Brasil" (BSF por Brazilian Sppoted Fever), su etiología era la Rickettsia rickettsii $(20,21)$. En los siguientes años la RMSF se confirmó en Colombia por el doctor Luis Patiño Camargo, cuando publicó el informe de una epidemia causada por Rickettsia sp (compatible con $R$. rickettsii) y fue llamada desde entonces "Fiebre de Tobia" (7), por el municipio 
donde se presentó dicho brote (Tobia, Cundinamarca). Más tarde se confirmó la enfermedad en México, Canadá, Panamá, Costa Rica y Argentina, esto indicó que se trataba de una enfermedad emergente y re-emergente en diferentes partes del mundo (22).

\section{Historia del Tifus murino}

La primera descripción clínica del tifus murino fue realizada en 1913 por Paullin en Atlanta, luego Neill estudió la enfermedad en cobayos, los cuales desarrollaban signos clínicos después una inyección intra-peritoneal de sangre de pacientes infectados con tifus (23-25). Desde la década de 1920, Mooser empezó a realizar estudios que condujeron a la diferenciación del tifus endémico y el tifus epidémico, importante para la descripción epidemiológica en diferentes partes del mundo (25-27). En esa misma década, el epidemiólogo Maxcy (28), sugirió que la transmisión del tifus endémico a los humanos se daba a través de la picadura de pulgas (Xenopsylla cheopis). Esto fue corroborado años más tarde por Mooser et al (29), quienes demostraron que el vector de la enfermedad eran las pulgas y los reservorios los roedores sinantrópicos (ratas y ratones domésticos). Luego se comenzó a describir la enfermedad en diferentes partes del mundo, en Grecia y Palestina en 1932 (30, 31), en Tunisia entre los años 1935-1936, se identificaron casos por la reacción Weil-Felix y cultivo animal (26). También se estudió la enfermedad en fauna silvestre en Kuwait, Tailandia, Norte del África, Egipto, Australia, Rusia, Francia y Sur América $(26,32)$. En la segunda mitad del siglo XX, luego de que se comenzó a efectuar un control radical de roedores sinantrópicos, la incidencia de tifus murino bajó considerablemente en los Estados Unidos, pero en otros países del viejo y el nuevo mundo, como; Kuwait, Egipto y Tailandia, entre otros, esta enfermedad es considerada como re-emergente (32-34).

\section{Historia del Tifus epidémico}

El síndrome clínico del tifus epidémico fue descrito por primera vez en el siglo XVI, en el Mediterráneo. El tifus epidémico según varios autores, es una enfermedad que ha causado más muertes que todas las guerras de la historia $(22,35)$. Se especula que el origen del tifus epidémico fue en Europa, donde causó grandes brotes de la enfermedad en la antigua Grecia (22). Se considera la enfermedad de las guerras debido a que ocasionó millones de pérdidas humanas en diferentes campos de batalla, por ejemplo en las batallas napoleónicas contra el imperio Ruso, donde produjo la muerte de aproximadamente 100.000 personas y en la Primera y Segunda guerra mundial donde también causó muchas bajas $(22,36-38)$. El doctor Charles Nicolle, director del instituto Pasteur en Túnez, fue el primero en demostrar en 1909, que el tifus epidémico era transmitido por el piojo humano (39). Luego Charles Nicolle, ganó el premio Nobel por su trabajo en el modelo de transmisión del tifus epidémico y años más tarde Stanislaus Von Prowazek y H. Rocha-Lima, descubren que el tifus es trasmitido a través de las heces del piojo más que por su picadura (40, 41). En las últimas décadas los brotes de tifus epidémico se focalizaron en lugares como Burundi (África) (42), Rusia en 1997 (43), Perú en 1998 (44), además de casos esporádicos en el norte del África $(45,46)$ y Francia (47). La bacteria que causa el tifus epidémico ( $R$. typhi), es considerada actualmente como un potencial agente de bioterrorismo por el CDC de Atlanta (22).

\section{Taxonomía}

Dentro del Filo alfa-proteobacterias, se encuentra el orden Rickettsiales, en el cual se incluyen a su vez las familias Rickettsiaceae y Anaplasmataceae (1). La familia Rickettsiacea incluye dos géneros, el ya mencionado Rickettsia y el género Orientia. El género Rickettsia está compuesto por los grupos Tifo (TG por sus siglas en ingles), el grupo de las Fiebres Manchadas de las montañas rocosas (SFG por sus siglas en ingles), el grupo transicional (TRG por sus siglas en ingles) y el grupo ancestral (AG por sus siglas en ingles). TG solo tiene 2 miembros, $R$. prowazekii y $R$. typhi, ambas patógenas para los seres humanos (2). En el SFG existen 20 especies: $R$. rickettsii (Rocky Mountain spotted fever), $R$. conorii subsp. conorii (Mediterranean spotted fever), $R$. conorii subsp. israelensis (Israeli spotted fever), $R$. conorii subsp. caspia (Astrakhan fever), $R$. conorii subsp. indica (Indian Tick Typhus), R. sibirica subsp. sibirica (Siberian tick typhus or North Asian tick typhus), R. sibirica subsp. mongolitimonae, R. australis (Queensland tick typhus), $R$. japonica (Japanese or Oriental spotted fever), $R$. africae (African tick bite fever), R. honei (Flinders Island spotted fever), $R$. slovaca, $R$. heilongjiangensis, $R$. aeschlimannii, $R$. parkeri, R. massiliae, $R$. marmionii, R. amblyommii, $R$. texiana y $R$. helvética. Todas las rickettsias de éste grupo son potencialmente patógenas para el hombre, siendo $R$. rickettsii la más virulenta (48). También se han identificado otras especies, pero no han sido asociadas con enfermedad en humanos (1, 49-51). En el grupo ancestral se encuentran $R$. belli y $R$. canadensis. Por último en el grupo transicional están $R$. akari y $R$. felis (2).

En los últimos años, luego de los avances en biología molecular, hubo una gran re-estructuración en el orden Rickettsiales y las familias que pertenecen a este orden fueron re-clasificadas así: de la familia Rickettsiaceae fueron removidas las especies Coxiela burnetii y Rickettsiella grylli 
y fueron re-ubicadas dentro de la familia Legionellaceae $(52,53)$, los géneros Eperythrozoon sp y Haemobartonella $s p$ se movieron a la familia Mycoplasmataceae (54), y por último, en la familia Anaplasmataceae encontramos en la actualidad los géneros Ehrlichia sp y Anaplasma sp (1).

Las bacterias del género Rickettsia, son pequeños agentes $(0,3$ a $0,5 \mu \mathrm{m}$ por 1 a $2 \mu \mathrm{m})$, cuya envoltura es típica de una bacteria Gram-negativa, con una doble membrana interna, una membrana de péptido-glicanos y una doble membrana externa. Son microorganismos intracelulares obligados, encontrándose libres dentro del citoplasma de las células eucarióticas, donde se dividen por fisión binaria. Las especies del SFG también se pueden encontrar dentro del núcleo (1).

\section{Ecología}

La transmisión transovárica en garrapatas, es el mecanismo de mantenimiento natural para todas la rickettsias del SFG, sin embargo la Rickettsia typhi (del Grupo tifus), $R$. akari, y $R$. felis del grupo transicional (TRG) pueden también tener transmisión transovárca (1). De hecho, para algunas especies de Rickettsia, como la $R$. peacockii, la transmisión transovárica parece ser el único mecanismo de supervivencia, mientras que para otras como la $R$. rickettsii, el microorganismo ejerce un efecto patológico en la garrapata (Dermacentor andersoni y Dermacentor variabilis, principales vectores en Estados Unidos) pudiendo eventualmente matarla, lo que conduciría a su propia extinción $(1,50)$. Se especula entonces que dicho efecto es compensado, por su habilidad de invadir y crecer en hospederos vertebrados tales como roedores silvestres (Microtus pennsylvanicus, reservorio en los Estados Unidos), creando así niveles suficientes y duraderos de rickettsemia para infectar estados larvales de los ectoparásitos $(1,50)$. El mecanismo descrito en vertebrados a dado lugar a los llamados reservorios "amplificadores" de la infección que será descrito más adelante. Adicionalmente, se ha descrito que la transmisión transovárica dependerá también de la carga infecciosa de las garrapatas, y que dicha forma de transmisión le confiere al ectoparásito, el ser considerado como reservorio. De acuerdo con lo anterior, no solo la infección de nuevas líneas de garrapatas sino también la regulación de la transmisión transovárica, lograrían favorecer el mantenimiento de un equilibrio a pesar de la muerte de muchas de las garrapatas infectadas $(1,50)$, (Figura 1).

En el estado de Sao Paulo (Brasil), donde se han incrementado los casos de rickettsiosis en los últimos 30 años, el estudio de las condiciones eco-epidemiológicas de la región ha permitido identificar varios de los anteriormente mencionados reservorios "amplificadores" para $R$. rickettsii tales como los capibaras (Hydrochaeris hydrochaeris), los roedores silvestres (Euryzygomatomys spinosus) y algunos marsupiales (Didelphis marsupialis), los cuales, al ser mordidos por la garrapata Amblyomma cajennense, especie vector de $R$. rickettsii en Sur América, ayudarían a mantener y explicar zonas de alta endemicidad para ésta infección en población humana (3).

En contraste con lo anterior, para R. typhi (Tifus Endémico), el mantenimiento por la transmisión transovárica es menos importante que la transmisión horizontal vía rickettsemia, ya que la bacteria se mantiene por largos periodos en sangre en los roedores del género Rattus, el cual es considerado el principal reservorio del tifus endémico. Este tifus, es transmitido por la pulga Xenopsylla cheopis que puede picar al ser humano al entrar en contacto directo con los roedores $(4,41)$, (Figura 2).

Por otra parte, en el ciclo de $R$. prowazekii (Tifus Epidémico) el piojo humano (Pediculus humanus corporis), no transmite la rickettsia verticalmente (transmisión del piojo a su descendencia), debido a que $R$. prowazekii mata el 100\% de los piojos infectados. Sin embargo se cree que en su ciclo natural la $R$. prowazekii utiliza a la ardilla voladora (Glaucoimys volans), sus pulgas (Orchopeas howardii) y sus piojos (Neohematopinus sciuropteri), como reservorios, sin producir daños o lesiones notables en el hospedero vertebrado ni en los invertebrados, mientras que el ciclo en los humanos se mantiene por medio de personas infectados persistentemente (1). El piojo tiene la tendencia de abandonar al hospedero febril, buscando un hospedero sano, con lo que dispersa efectivamente la infección entre la población humana y en 1 a 2 semanas luego de adquirir la infección el piojo muere. Ver figura 2

\section{Patogénesis}

El ser humano participa dentro del ciclo de rickettsia como un hospedero accidental y la transmisión se da por medio de la saliva cuando la garrapata, ácaro y pulga (invertebrados hematófagos), se están alimentando o en el caso del tifus, la entrada de la rickettsia se da por piel cuando el humano esparce las heces en la picadura que causó el piojo, pero también puede existir la posibilidad de entrada por mucosas (1). Ejemplo de lo anterior, es la infección por la vía conjuntival; y la vía aérea a los pulmones (accidentes en laboratorio o eventos de bioterrorismo). La diseminación dentro del organismo se da inicialmente por vasos linfáticos y luego por vasos sanguíneos a todos los órganos. Las células endoteliales seguidas por los macrófagos son los blancos principales de las rickettsias (en el caso de R. akari, los 


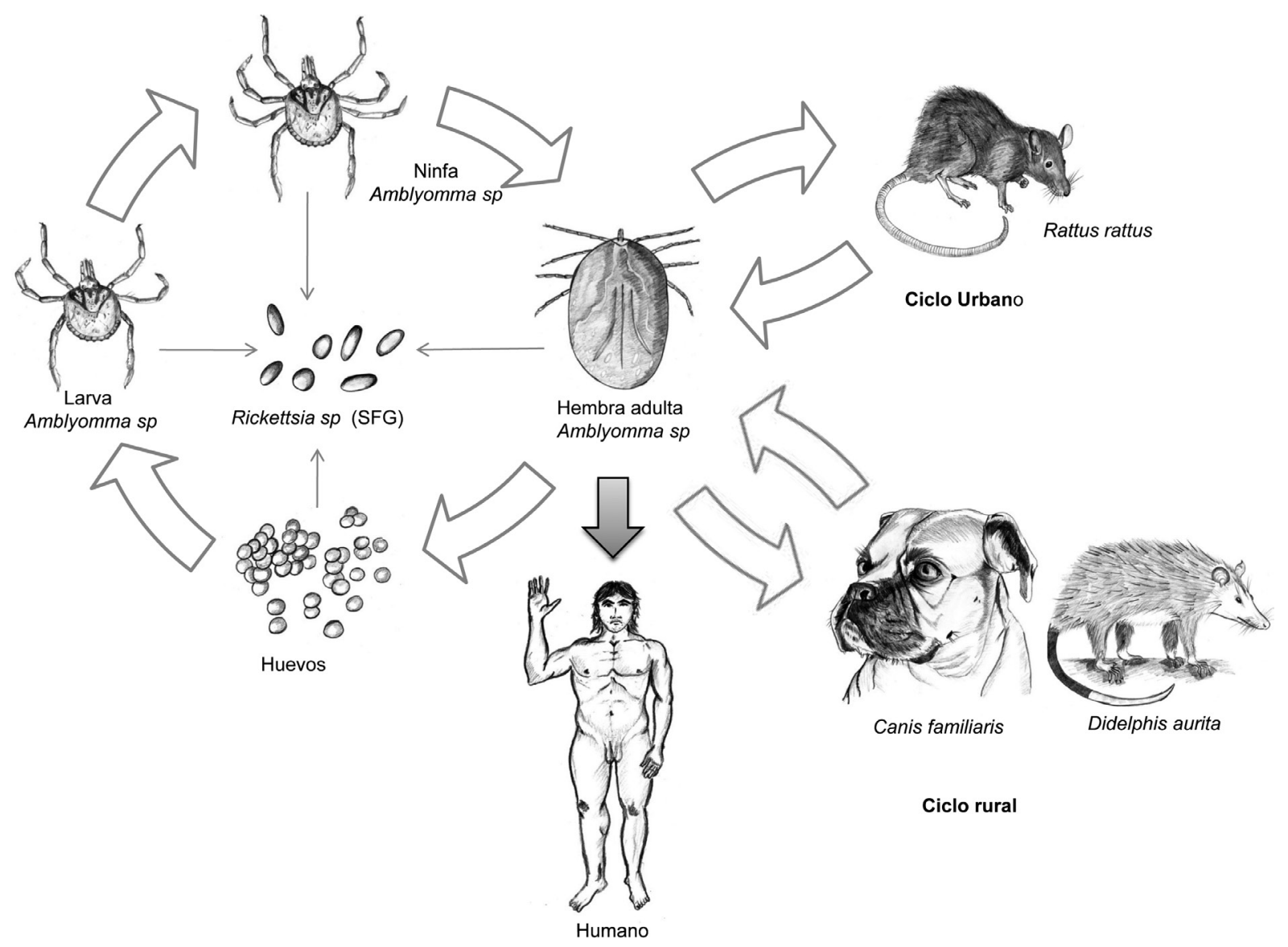

Figura 1. Ciclo de vida para el grupo de las Fiebres manchadas (SFG). 1. Garrapata ingurgitada y adulta puede adquirir la infección y transmitirla por la vía transovárica y transestadial. Los tres estadios de la garrapata pueden ser potenciales vectores de la enfermedad y transmitirla a los reservorios. 2. Existe el ciclo urbano donde los principales reservorios de la enfermedad serían roedores sinantrópicos. 3. El ciclo rural donde podrían participar los caninos y algunos marsupiales como reservorios de la enfermedad. 4. Cuando el humano entra en contacto con los vectores (a través de la picadura) por la convivencia o la exposición accidental con los reservorios, adquiere la enfermedad. Adaptado de Azad y Beard, 1998 (55).

macrófagos son la primera célula blanco de infección). Se ha demostrado que rickettsias como la $R$. conorii, se unen a la célula a través de las moléculas conocidas Ku70 (proteína kinasa dependiente de DNA), usando como ligandos sus proteínas de membrana externa OmpA, OmpB, péptido B, Adr1 o Adr2 (57). Dicha interacción induciría un re-arreglo en el citoesqueleto, que resulta en la entrada de la bacteria por medio de un fagosoma, posteriormente la bacteria se multiplica por fisión binaria (58) y lisa rápidamente la membrana fagosomal para escapar al citoplasma, donde sobrevive gracias a la liberación de factores de secreción IV(T4SS), los cuales desencadenan en la célula infectada, la síntesis y secreción de nutrientes (59). La bacteria adquiere un fenotipo diferente para su desplazamiento célula a célula y se disemina a través de mecanismos de polimerización de actina (58-61).

Luego de que las células endoteliales han sido infectadas por las rickettsias, comienzan a producir diferentes tipos de citoquinas como: IL-1, IL-3, IL-5, IL-6, IL-7, IL-11, IL-14, IL- 15 , TGF- $\beta$, GM-CSF, M-CSF, PDGF, TNF- $\alpha$, ICAM-1, prostaglandinas, IL-8, MCP-1, gro, ENA-78, RANTES, IP10 y Mig $(58,62)$. Sin embargo existen dos citoquinas, el INF- $\gamma$ y el TNF- $\alpha$ que son bactericidas para las rickettsias, estas debido a que estimulan la producción de óxido nítrico $(58,63)$. Luego de que se da este proceso en las células endoteliales, comienza una respuesta inmune tipo Th1 (de patógenos intracelulares), con un aumento en la producción 


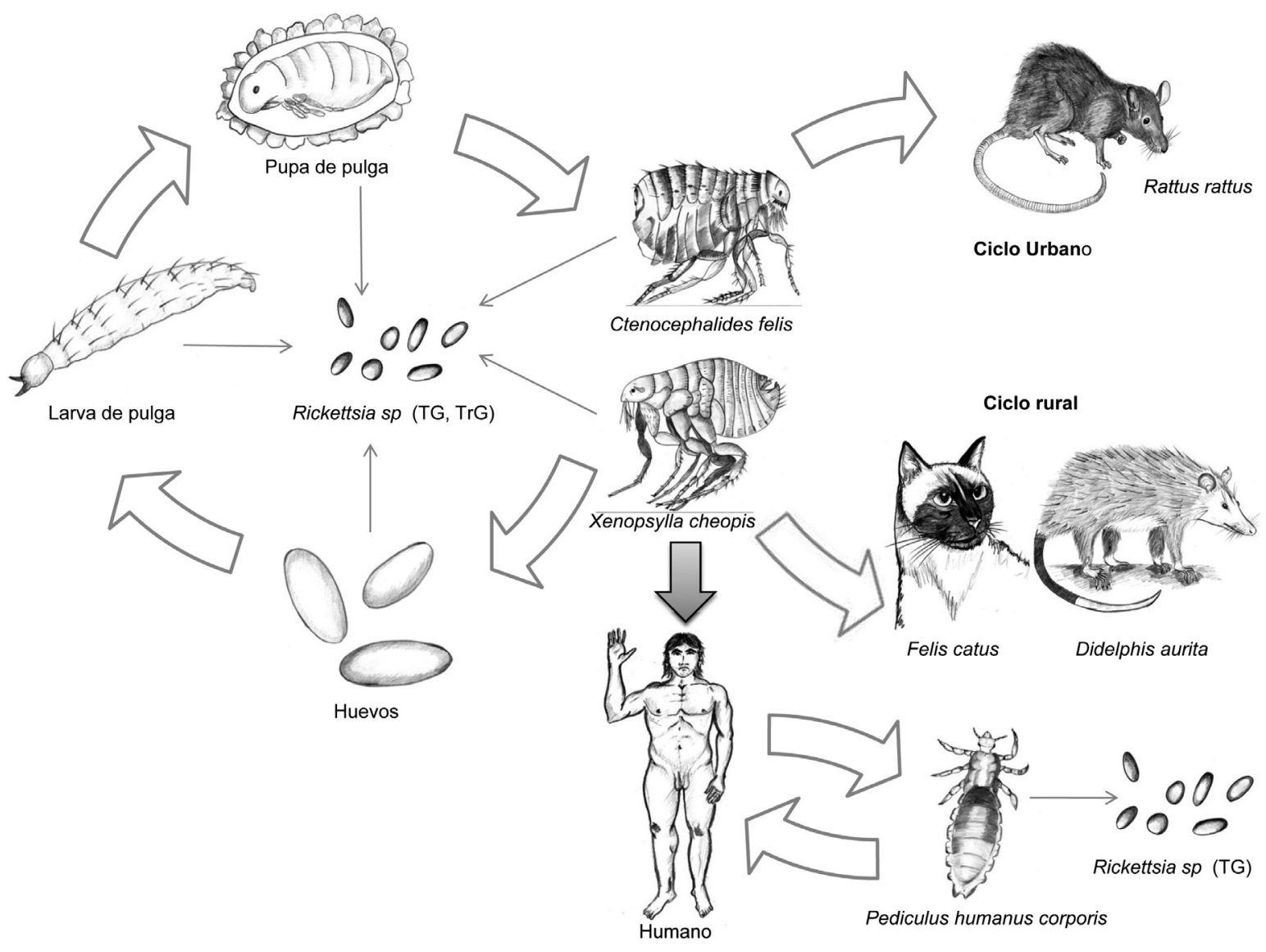

Figura 2. Ciclo de vida para el grupo tifus (TG). 1. Las pulgas de los géneros Xenopsylla cheopis y Ctenocephalides felis son los principales vectores de la Rickettsia typhi que al adquirir la infección la transmiten de manera transovárica y transestadial pero solo los individuos adultos transmiten la infección a los reservorios y humanos. 2. Existe el ciclo urbano donde los principales reservorios de la enfermedad serían roedores sinantrópicos. 3. El ciclo rural donde podría estar la participación de felinos y algunos marsupiales como los reservorios de la enfermedad. 4. Cuando el humano entra en contacto con los vectores (a través de la picadura y las heces de la pulga) por la convivencia o la exposición accidental con los reservorios, adquiere la enfermedad. 5. El principal vector de la Rickettsia prowazekii es el piojo Pediculus humanus corporis que le transmite la enfermedad a través de las heces que deposita en el momento que pica a el humano. Los piojos se pueden infectar entrando en contacto con humanos persistentemente infectados. Adaptado de McElroy et al, 2010 (56).

de INF- $\gamma$ y el TNF- $\alpha$ por parte de los linfocitos T CD 8+ y la células NK. Estas células inmunes son estimuladas por los linfocitos T CD 4+ (Th1) y el resultado final es una respuesta citotóxica para posteriormente estimular la apoptosis de la célula infectada $(58,64)$. El mantenimiento de la respuesta inmune Th1, también se da por las citoquinas IL-2 y IL-12 las cuales se producen a partir de monocitos o macrófagos $(65,66)$.

La inmunidad humoral o Th2 se da por la presentación de antígenos provenientes de las proteínas OmpA y OmpB principalmente a los linfocitos B. En general existe una relación negativa en los primeros días de la infección, en cuanto a los niveles de INF- $\gamma$ e IL-12 con la producción de anticuerpos, a mayor INF- $\gamma$ e IL-12, menor es la producción de anticuerpos. La respuesta humoral es muy importante en los casos de re-infección y también para la eliminación de la bacteria en el periodo de convalecencia de la enfermedad (58).

La invasión a las células endoteliales por parte de la bacteria, crea un aumento en la permeabilidad vascular, causando así un edema a nivel de los tejidos afectados, y produciendo hipovolemia. El edema producido, puede amenazar la 
vida del paciente cuando se presenta en los pulmones y el cerebro; y se asocia también con fallas en el drenaje linfático. Igualmente, la baja perfusión sanguínea pude generar daños renales, isquemia en extremidades con secuelas permanentes por pérdida de la irrigación, además de otros órganos y propiciar así una falla multi-orgánica (60). Se ha especulado, que el daño a nivel tisular causado por la falta de nutrientes y oxígeno, la hipovolemia y el edema pulmonar, se podría también sumar la coagulación intravascular diseminada (CID), empeorando el cuadro clínico y la letalidad de la enfermedad, debido a las abundantes hemorragias que se pueden presentar (60).

El período de incubación de la enfermedad en humanos es de 10 a 14 días y en la fase aguda se presentan fiebre alta $\left(>\right.$ a $\left.38^{\circ} \mathrm{C}\right)$, dolor de cabeza y brote en la piel del tronco, las extremidades, alrededor de las axilas y en la palma de las manos, en 5 a 7 días después de los primeros síntomas (41). A nivel neurológico se presenta un síndrome meníngeo, con estupor y coma, esta enfermedad puede ser fatal hasta en un 10 a $30 \%$ de los pacientes (41). Se ha reportado que los pacientes con RMSF, pueden presentar ausencia del brote en la piel y hasta en un 50\% de los pacientes se pueden presentan nauseas, vómito y otros síntomas de infección gastrointestinal, como signos tempranos de infección (67).

En un estudio realizado en Perú, se encontró que los signos y síntomas, más frecuentemente asociados al tifus epidémico fueron: escalofríos $(65,2 \%)$, postración $(52,2 \%)$, mialgias $(52,2 \%)$ y anorexia $(39,1 \%)$. Curiosamente, unicamente dos casos $(8,7 \%)$ presentaron brote en piel y estos brotes se observaron en zonas no expuestas (4). Existen cuadros clínicos de otras enfermedades como influenza, dengue, fiebre tifoidea, malaria, leptospirosis, arbovirus, enterovirus, arenavirus y hantavirus entre otros, que exhiben síntomas y signos comunes (la mayoría generales e inespecíficos), los cuales también son frecuentemente descritos en casos confirmados de tifus. La variabilidad de los síntomas explicaría por qué, inclusive en áreas donde el tifus es bien conocido por la comunidad médica, el diagnóstico clínico se hace sólo entre el 5 a 10\% de los casos, lo que tiene un efecto desfavorable en el pronóstico de la infección (4).

\section{La enfermedad en los animales domésticos}

Los caninos y felinos son los animales domésticos donde más se han estudiado las rickettsias, en Brasil se llevó a cabo un estudio experimental de hallazgos de laboratorio en caninos infectados con $R$. rickettsii (68), el cual mostró que los perros inoculados experimentalmente presentaban anormalidades hematológicas y signos clínicos como descarga ocular bilateral, congestión en esclerótica, edema conjuntival, anorexia, fiebre y letargia. En algunos perros la rickettsemia se presentó en el día 2 post infección, sin embargo en éste estudio los perros no presentaron hemorragias ni signos nerviosos (68). Un estudio adicional llevado a cabo en el mismo país, demuestra la presencia en caninos de anticuerpos contra Rickettsia sp en diferentes localidades del sur (69). En dicho trabajo se tomaron 389 muestras de suero de caninos y se evaluaron por Inmunofluorescencia Indirecta (IFI) utilizando antígenos de $R$. rickettsii, $R$. parkeri, $R$. amblyoommii, $R$. rhipicephali y $R$. belli. El $42,4 \%$ de los perros presentaron títulos de anticuerpos de clase IgG al menos contra una de las especies de Rickettsia. El 25\% de los perros presentaron un título de anticuerpos contra $R$. parkeri, 4 veces mayor al título de anticuerpos obtenido contra las demás especies de rickettsias. Con base en éste resultado, los autores concluyeron que la especie que mas pudo infectar estos perros en la región del sur fue la $R$. parkeri. Adicionalmente, en el mismo trabajo se encontró que los caninos infectados exhibían como factor de riesgo el contacto directo previo con pasturas o regiones forestales (69).

Otros estudios desarrollados en EU, han mostrado la amplia diseminación de la Rickettsia en ese país. En el primero de ellos, un estudio retrospectivo llevado a cabo por el United States Department of Agriculture (USDA), se encontró una frecuencia de infección del $43 \%$ por $R$. rickettsii en caninos empleando una muestras seleccionadas de manera aleatoria (70). Más tarde un estudio epidemiológico llevado a cabo en Washington D.C, y en los estados de Maryland, Mississippi, Connecticut y Ohio, en caninos infectados con rickettsias del grupo de las fiebres manchadas, se reportaron daños sistémicos en cerebro como encefalitis e hidrocefalia obstructiva secundaria, además en testículo se reportó eritema y edema en túnica vaginal del escroto, hemorragia testicular y epididimitis (71).

Estudios en otros países de Sur América, muestran también la importancia de la infección en caninos y otros animales domésticos. Un reporte del año 2007 en regiones urbanas de Santiago en Chile, registró dos casos clínicos de caninos que presentaron signos tales como decaimiento, quejido, paresia de extremidades posteriores, melena, hematemesis, linfadenopatía, dolor lumbar, escasas petequias en las mucosas y conjuntivitis (72). Entre los hallazgos de laboratorio se evidenciaron anemia, trombocitopenia, leucocitosis leve con neutrofilia y linfopenia, aumento de GPT (Transaminasa glutámico-pirúvica), hipoalbuminemia e hipoglobulinemia y una frecuencia de infección evaluada por IFI (con placas con antígeno de R. conorii), del 35\% (27/77) (72). 
En Colombia, específicamente en Villeta, Cundinamarca, se tomaron aleatoriamente muestras de sangre en caninos y equinos, en estos animales se encontró una reactividad alta en algunos casos con títulos de (1:8192) por IFI para rickettsias de las fiebres manchadas, lo que permitió proponer que estos animales podrían servir como centinelas de la rickettsiosis (73). En concordancia con lo anterior, un estudio previo llevado a cabo por el Departamento de salud de Mississippi, había concluido que los caninos pueden ser usados como centinelas de esta enfermedad (74).

Investigaciones llevadas a cabo en otras especies domésticas, demuestran la amplia diseminación de las bacterias del género Rickettsia en la naturaleza. En los Estados Unidos se estudió la prevalencia de infección por PCR (Polimerase chain reaction) y de títulos de anticuerpos evaluados por IFI en felinos, encontrándose una muy baja asociación entre los resultados obtenidos por PCR y por IFI. Por PCR a partir de DNA extraído de sangre, no se encontró ningún felino positivo y por IFI de placas antigenadas con $R$. rickettsii y $R$. felis se encontraron $6(6,6 \%)$ y $2(2,2 \%)$ animales positivos respectivamente (75). En California y Wisconsin entre los años 2001 y 2003, se estudió la seroprevalencia para rickettsias de diferentes grupos en gatos domésticos, gatos de albergue y gatos salvajes (170 animales), encontrándose frecuencias de infección de 17,2\% para $R$. rickettsii, 14,9\%, R. akari, $4,9 \%$ R. typhi y $11,1 \%$ para $R$. felis (76).

\section{Los animales silvestres como reservorios de la rickettsiosis}

Aunque técnicamente la garrapata es considerada el reservorio natural de $R$. rickettsii, en la medida en que se infecta de por vida transmitiendo la infección no solo de manera transestadial, si no también trans-ovarialmente, debido tanto a la capacidad patogénica de la bacteria, como a los bajos porcentajes de infección natural en poblaciones silvestres de garrapatas, se ha estimado necesaria la presencia de los llamados reservorios "amplificadores" de la infección (3). Estos últimos, son principalmente mamíferos, que siendo susceptibles tanto a la infección por $R$. rickettsii, como a la mordedura de la garrapata, cumplen con las condiciones mínimas para ser a su vez fuente de infección de garrapatas no infectadas, ayudando así a la diseminación del microorganismo en zonas endémico / enzoóticas. Entre las características necesarias para ser considerados buenos reservorios amplificadores, Labruna describe: 1) la susceptibilidad a la infección con $R$. rickettsii, 2) su abundancia en las zonas antes mencionadas, 3) la detección de largos períodos de bacteremia y 4) la prolificidad reproductiva que permita la disponibilidad casi permanente de un abundante número de animales susceptibles a la infección aguda. Los siguientes estudios corresponden a los animales candidatos a cumplir con éstas características en las regiones donde se presenta habitualmente la enfermedad humana (3).

En Brasil se estudió la participación de la Didelphis aurita como un potencial reservorio. Los hallazgos de laboratorio permitieron evidenciar gran rickettsemia mantenida por largos periodos que hacen de estos marsupiales potenciales diseminadores de la infección. Cobayos inoculados intraperitonealmente con sangre de los marsupiales infectados resultaron a su vez infectados con $R$. rickettsii. En éste estudio se pudo demostrar que garrapatas Amblyomma cajennense de los estadios de ninfa y adulto infectados, transmitían la infección a marsupiales, desde el día 5 hasta el día 25 postexposición. Los D. aurita inoculados intra-peritonealmente desarrollaron anticuerpos reactivos contra $R$. rickettsii en el día 4 y en el día 12 para los que se infestaron con garrapatas A. cajennense infectadas con $R$. rickettsii. A pesar de la infección, los marsupiales no mostraron cambios marcados en sus valores hematológicos (77)

También en Brasil se estudió la infección experimental de capibaras (Hydrochoerus hydrochaeris) con $R$. rickettsii y la posterior transmisión a garrapatas de la especie $A$. cajennense. En este estudio se encontró la rickettsemia desde el día 9 post infección y se mantuvo hasta el día 15 en capibaras infestados con garrapatas infectadas con $R$. rickettsii y desde el día 6 post infección hasta los días 27-30 en capibaras inoculados intraperitonealmente con $R$. rickettsii. Estos capibaras infectados mostraron una leve disminución en el número de eritrocitos, promedio de volumen corpuscular (PVC) y concentración de hemoglobina en los días 15 y 28 post infección. El desarrollo de anticuerpos contra $R$. rickettsii se inició el día 12 post infección en capibaras infestados con garrapatas infectadas con Rickettsia rickettsi y el día 6 post infección en capibaras inoculados intraperitonealmente con $R$. rickettsii (78).

Finalmente, en Nebraska, Estados Unidos, se estudió la frecuencia de infección por $R$. rickettsii en coyotes (Canis latrans) y mapachaes (Procyon lotor), utilizando la IFI como método diagnóstico. En esta zona se encontró una frecuencia de infección para coyotes del $13 \%$ en 64 animales muestreados y en mapaches no se evidenció ningún animal seroreactivo (79).

Lo anterior indica que se requieren más estudios para determinar la importancia de estos y otros animales silvestres como candidatos a posibles reservorios amplificadores en las zonas mencionadas. 


\section{Importancia epidemiológica}

Las bacterias del género Rickettsia, pueden ser patógenas para hospederos vertebrados e invertebrados, varias de las especies de este género han sido la causa de numerosas epidemias en todo el mundo. Algunas de los más importantes brotes registrados en la historia son el de tifus, que causó dos millones de muertes en el año de 1576 en México (80) y tres millones de muertes entre los años 1917 y 1923 en Rusia (50); y la RMSF, que produjo 224 muertes durante 1983 en los Estados Unidos (67). Desde su reconocimiento a principios del siglo XIX en los Estados Unidos, la RMSF ha venido causando enfermedades a lo largo de todo el país, excepto en los estados de Maine y Vermont. En los últimos 20 años, ha cobrado gran importancia debido a la aparición de otras enfermedades también transmitidas por garrapatas tales como la enfermedad de Lyme, la erlichiosis, la anaplasmosis y la babesiosis humanas. Como muestra de lo anterior, vale la pena mencionar que entre 1996 y el 2000, se reportaron al CDC de Atlanta, aproximadamente 2700 casos (67).

En Centroamérica, en el año de 1941, se presentó otro brote de tifus en México, con 1166 muertes, donde el estado más afectado fue Nuevo León. Posteriormente se presentaron brotes de tifus epidémico en Galena en 1963 y otro de tifus murino en Montemorelos en 1996, donde también se identificaron rickettsias del SFG, en garrapatas Rhipicephalus sanguineus y Amblyomma cajennense, presumiblemente de la especie $R$. rickettsii (81). Un estudio realizado en el estado de Nuevo León (México), en 1997 reveló que de 345 pacientes, el 25\% presentaba reactividad a los anticuerpos de las rickettsias del grupo tifus (82).

En Sur América se han descrito varios brotes de infección por bacterias del género Rickettsia, en diferentes países (83). En Brasil R. rickettsii fue descrita desde 1920, como el agente causal de la fiebre manchada Brasileña (BSF, Brasil Spotted Fever), la cual es trasmitida por el vector Amblyomma cajennense (84). En Uruguay en 1990, se presentaron casos de Fiebre manchada diagnosticados por IFI en los cuales el vector incriminado fue la garrapata Amblyomma maculatum, que fue recolectada de mascotas caninas (85). Así mismo, en Argentina en 1999 se diagnosticaron infecciones por Rickettsia del SFG, en pacientes de la provincia de Jujuy, a través de un programa de vigilancia epidemiológica para detectar anticuerpos que reaccionaron contra $R$. rickettsii, $y$ en esta ocasión se identificó como vector a Amblyomma cajennense. Estas garrapatas fueron recolectadas del medio ambiente y de algunos mamíferos como caballos y mascotas (86-88). En Perú a diferencia de los anteriores, el tifus del TG, es el de mayor presentación. En 1985 se registró un brote en dos comunidades rurales de Cuzco y desde 1989 hasta 1999 se han notificado casos de tifus endémico en Ancash, Arequipa, Cuzco, Huanuco, Piura y Puno. Estas zonas se describieron como endémicas para la enfermedad lo que constituyó un problema en la salud pública regional. En estos casos, también $R$. felis se identificó en pulgas (Ctenocephalides canis), de animales domésticos. Así mismo se describieron otras zonas endémicas confinadas a algunos escenarios de la sierra sur (Apurímac y Ayacucho) $(4,5,86)$.

Como ya se mencionó anteriormente, existe un importante cuerpo de evidencia serológica y molecular que muestran el importante papel epidemiológico que otros vertebrados, tales como los cánidos domésticos y silvestres, pueden estar jugando para el mantenimiento de la infección en algunas regiones de Sur América (87-89).

Además de los vectores mencionados hasta éste punto, también se ha demostrado la infección por bacterias del género Rickettsia en garrapatas Haemaphysalis juxtakochi, Haemaphysalis leporispalustris, Amblyomma parvum, Amblyomma neumanni, Amblyomma aureolatum, Amblyomma longirostre, Amblyomma ovale, Amblyomma cooperi, Ixodes loricatus, y en pulgas Polygenis $s p$ y Anomiopsyllus nudata (89-99).

En Colombia, como ya se mencionó, el primer brote documentado de rickettsiosis de SFG sucedió entre 19341936 en la región de Tobia, Cundinamarca, allí sufrieron la enfermedad 65 personas de diferentes edades, 62 de las cuales murieron a causa de la enfermedad dejando una tasa de letalidad del 95\%. Estos primeros reportes de la enfermedad se hicieron gracias al Doctor Luis Patiño, quien describió el brote y demostró que este era producido por bacterias compatibles con Rickettsia sp (7). Setenta años más tarde (en el 2005), se realizó un estudio de seroprevalencia, para $R$. rickettsii en una población general en Villeta, Cundinamarca, donde se tomaron 392 muestras de suero de humanos sanos adultos, que fueron analizadas por IFI para la detección de anticuerpos de clase IgG. A partir de este trabajo (donde se utilizó como criterio de positividad, la presencia de anticuerpos en una dilución de 1:64), y se estableció una tasa de seroprevalencia de 40,2\% (149/371, CI 95\%: 35,6-45,6). En dicho estudio no se encontró asociación entre una prueba positiva y las variables sexo, edad, ocupación, nivel de educación, material de construcción de la vivienda, circulación de animales domésticos dentro y fuera de casa, ni el tiempo de permanencia en el área o el número de personas que vivían en la casa. No obstante, la seropositividad fue menor entre aquellas personas que refirieron contacto previo con diferentes estados del vector como son la ninfa (OR:0,53, IC95\%:0,32-0,89) y la larva (OR:0,59, IC95\%:0,20-1,66) (86). 
Posteriormente, en el departamento de Antioquia, en la primera semana del mes de marzo de 2006 se notificó tanto al Ministerio de la Protección Social como a la Dirección Seccional de Salud de Antioquia, por parte del Ejercito Nacional de Colombia, sobre la ocurrencia de tres casos fatales de síndrome febril hemorrágico con compromiso pulmonar agudo en un batallón de 38 soldados campesinos que patrullaban el municipio de Necoclí, Antioquia. En este caso, se establecieron como diagnósticos diferenciales de la infección: dengue, malaria, fiebre amarilla, hepatitis viral, hantavirus y leptospirosis, entre otras. Posteriormente, tanto la información clínica como los datos provenientes de la investigación epidemiológica de campo, permitieron establecer la sospecha de ricketsiosis que fue confirmada por el laboratorio del CDC de Atlanta en 7 de los 14 casos estudiados para Rickettsia rickettsii, de los cuales 3 soldados y 2 civiles fallecieron por la enfermedad. A partir de este momento, se decidió introducir en el protocolo del síndrome febril, la enfermedad de Fiebre Manchada como el principal causante del brote en la región y se estableció un programa de vigilancia epidemiológica para esta entidad en la zona afectada (8).

Durante el 2007, esta vez en el municipio de Los Córdobas, (noroeste del departamento de Córdoba), que limita al oeste con Arboletes en el Urabá antioqueño, se notificaron casos similares que iniciaron síntomas entre el 14 de febrero y el 8 de marzo de 2007 (23 días). Los casos en Los Córdobas presentaron fiebre, dolor de cabeza $(94 \%)$, dolor retroocular $(88 \%)$, artralgias $(72 \%)$, malestar general $(66 \%)$, mialgias $(61 \%)$, dolor abdominal (61\%), vómito (55\%), diarrea $(44 \%)$ y rash en baja frecuencia $(18 \%)$, además se presentaron hallazgos de laboratorio como neutrofilia (60\%), leucocitosis (50\%) y trombocitopenia (40\%). En este brote se confirmó el género Rickettsia por inmunohistoquímica y seroconversión $(6,9)$. En este brote se presentó una tasa de mortalidad de $36 \%$ (4 muertes de 11 casos) y una tasa de infección de $1.25 \%$ (11 casos confirmados de una población de 874 personas) para la población del municipio. Otro hallazgo de este brote fue la presencia de anticuerpos IgM contra el virus dengue en una de las muestras perteneciente a uno de los casos mortales y cinco muestras con reactividad de IgM contra Leptospira (9).

A finales del 2007 y a principios del 2008, se presentaron en el corregimiento Alto de mulatos, Turbo, 15 pacientes con sintomatología compatible con rickettsiosis. Las manifestaciones clínicas reportadas fueron fiebre (100\%), mialgias $(86,7 \%)$, vómito $(60 \%)$, artralgias $(60 \%)$, dolor abdominal $(53,3 \%)$, cefalea $(53,3 \%)$, dolor retro ocular $(33,3 \%)$, ictericia $(26,7 \%)$ y erupción $(20 \%)$; en menor proporción se reportó oliguria y la existencia de petequias (6). En esta ocasión, los 15 casos fueron confirmados con rickettsiosis, 11 fueron hospitalizados para observación y manejo, dos pacientes más ingresaron muertos al hospital y los dos restantes recibieron manejo ambulatorio. En total, incluidos los dos pacientes que ingresaron muertos al hospital, cuatro pacientes fallecieron para una letalidad de $26,6 \%$ durante este brote (6).

Finalmente, en el departamento de Caldas (Colombia), se diagnosticó Rickettsia typhi por IFI en 14 pacientes de 120 con síndrome febril que habían sido previamente positivos para la reacción de Weil-Felix (100). Ésta es la primera evidencia de infección humana por ricketsiosis endémica en nuestro país, y establece la necesidad de su búsqueda en otras regiones de ecología similar, donde muchos casos de síndromes febriles indiferenciados permanecen sin diagnóstico definitivo debido a la carencia de pruebas inmunológicas más específicas.

\section{Vacunas}

El estudio indirecto de las vacunas contra la rickettsiosis, comenzó con el desarrollo de armas biológicas en la antigua Unión Soviética y Japón en los años 30, estas armas fueron hechas a partir de diferentes especies de Rickettsia. Desde la década de los 40 las bacterias eran utilizadas en forma de aerosol y por inhalación inducían la enfermedad en diferentes animales de laboratorio, esto comenzó a indicar otras probables vías de infección o de posible vacunación (101, 102).

A partir de estos avances se desarrollaron dos tipos de vacunas contra infecciones rickettsiales, vacunas con la bacteria muerta y con bacterias vivas atenuadas, las cuales fueron evaluadas en humanos con diferentes resultados. En 1924 Spencer y Parker, desarrollaron una vacuna contra la RMSF, fabricadas a partir de garrapatas infectadas que luego eran expuestas a cobayos. La vacuna se realizó a partir de la bacteria (Rickettsia) que creció en los tejidos de la garrapata, la cual posteriormente fue tratada con fenol y formaldehido. Esta vacuna no previno la infección pero la fatalidad por la infección se redujo notablemente en los individuos vacunados (103). Años más tarde se comenzó a utilizar la metodología del cultivo de Rickettsia en embriones de pollo que fue desarrollada por Cox, este seguro y fácil método fue adoptado para la producción de vacunas con bacterias muertas (101). Para el año de 1930 Rudolf Weigl, desarrolla una vacuna contra tifus, que sin embargo resulta ineficiente, pues muchas de las personas que participaron en el ensayo, desarrollaron la enfermedad y murieron durante el experimento $(40,41)$. Las vacunas con bacterias vivas atenuadas y muertas, fueron probadas en humanos en 1973, pero todos los individuos vacunados desarrollaron la 
enfermedad después de un prolongado periodo de incubación (104). En 1970 la USAMRIID (U.S. Army Medical Research Institute of Infectious Diseases) desarrolló una vacuna inactivada con la bacteria ( $R$. rickettsii) muerta, a partir del cultivo de fibroblastos provenientes de embrión de pollo (105). Cuando esta vacuna fue probada en humanos en 1983 protegió el $25 \%$ de los individuos vacunados, además hubo más rápida recuperación de los síntomas con los individuos que se enfermaron, cuando eran tratados con tetraciclinas $(101,106)$.

Luego se comenzaron a estudiar los antígenos de membrana externa (OmpA y OmpB) como potenciales epítopes para la producción de vacunas contra la infección de $R$. rickettsii y $R$. prowazekii (107). Los anticuerpos producidos contra OmpA y OmpB, se administraron pasivamente en cobayos y ratones, protegiéndolos de la infección contra $R$. rickettsii y R.conorii (101, 108-110).

Más tarde, otros estudios apoyaron la idea de que hay mecanismos de protección cruzada entre la inmunidad inducida por la vacuna y otros mecanismos inmunes que contribuyen con la inmunidad protectora. Los ratones inmunizados con una infección sub letal con microoganismos del SFG estrechamente relacionado con $R$. australis o $R$. conorii, sobrevivieron con dosis letales de un organismo heterólogo (111). En otra investigación de protección cruzada entre dos bacterias filogenéticamente distantes ( $R$. typhi y R.conorii), que además se ha comprobado no tienen reacción serológica cruzada, mostraron una protección celular muy similar debida a los linfocitos $\mathrm{T}(101,112)$.

Según Walker (2009), la protección sería más eficiente cuando se utilizan vacunas basadas en antígenos conformacionales en las rickettsias, como el Omp A y el Omp B, para que se de una estimulación de memoria de células T CD 8+y CD 4+ y se de una respuesta inmune de protección contra infecciones futuras en individuos vacunados (101).

\section{Diagnóstico}

Existen pruebas inmunológicas tanto directas como indirectas para el diagnóstico de la infección por bacterias del género Rickettsia. Entre las primeras podemos mencionar la prueba de inmunohistoquímica (IHQ), que se ha estandarizado para la detección de rickettsias en biopsias de piel con lesiones de brotes $(113,114)$. En segundo lugar encontramos la prueba de IFI, con un anticuerpo policlonal conjugado a fluoresceína, que reacciona con $R$. rickettsii, $R$. conorii y $R$. akari, y que ha sido útil para muestras con lesiones congeladas, fijadas en formalina o embebidas en parafina (115). Como pruebas indirectas podemos mencionar las pruebas serológicas tales como la IFI, que es considerada la prueba de oro y finalmente, tenemos también las pruebas de inmuno-peroxidasa indirecta, aglutinación en látex y el ensayo inmuno-enzimático (EIA) (116). La prueba comercial de IFI para detección de anticuerpos contra Rickettsia, contiene todas las proteínas antigénicas sensibles al calor y los lipopolisacáridos comunes al grupo antigénico (116). Se dispone de estuches en diferentes casas comerciales tanto para diagnóstico de la RMSF y de tifus, ejemplo de esto son las casas Pan Bio (Baltimore, MD, Estados Unidos), Focus Technologies (Cypress, CA, EU) y Bio Mérieux (Marcy l’Etoile, Francia).

De otro lado, existen también las pruebas moleculares, tales como la PCR, aplicada en la amplificación de DNA de $R$. rickettsii, $R$. conorii, $R$. japónica, $R$. typhi, $R$. prowazekii, $R$. africae, $R$. felis, $R$. helvetica, $R$. belli y $R$. slovaca $(92,117$, 118 ), donde usualmente se emplea como muestra, la sangre periférica, la capa de mononucleares de sangre periférica (MNSP), o el plasma, pero también, ocasionalmente se realiza a partir de muestra de tejido fresco, congelado o embebido en parafina de pacientes y vectores (88). El gen de la Citrato sintetasa de la bacteria, ha sido el principal blanco para la amplificación de todas la especies patógenas de Rickettsia $(88,90,92)$. Los genes $O m p A$ y $O m p B$, que también se amplifican para ser secuenciados, han sido más utilizados en trabajos de identificación de especie $(81,88,119-121)$.

Recientemente se planteó una prueba diagnóstica de hibridación fluorescente in situ a partir de biopsias de piel y de órganos, que como ventaja exhibe el no presentar problemas de reacciones cruzadas entre los grupos de rickettsias (122).

\section{Tratamiento}

El tratamiento de elección para la RMSF es la Doxiciclina a dosis de $200 \mathrm{mg} /$ día, por 10 días, aunque también se usan otras tetraciclinas. Otras alternativas que se han sugerido, incluyen las fluoroquinolonas y la Claritromicina, pero su efecto es controvertido $(67,116,118)$. Parola et al (48), describieron el tratamiento de RMSF, en la cual se plantea el uso de diferentes antibióticos (Doxiciclina, Claritromicina, cloranfenicol, Azitromicina y Josamicina) para diferentes grupos etarios y estados fisiológicos (mujeres embarazadas), (Tabla 1).

Hay que tener en cuenta que estos medicamentos tienen sus contraindicaciones en las diferentes edades de los pacientes, por ejemplo el cloranfenicol administrado en neonatos puede producir distensión abdominal y colapso vasomotor con palidez y cianosis. Este antibiótico se debe utilizar solo cuando en el paciente es contraindicado el uso de Doxiciclina. Las tetraciclinas son contraindicadas 
Tabla 1. Tratamiento para la RMSF en los diferentes grupos etarios y estados fisiológicos (mujeres embarazadas)

\begin{tabular}{|c|c|c|}
\hline Rickettsiosis & Paciente & Tratamiento antibiótico \\
\hline \multirow{9}{*}{ Fiebre manchada del Mediterráneo } & \multirow{4}{*}{ Adultos } & Doxiciclina, dos dosis orales $200 \mathrm{mg}$ cada $12-\mathrm{h}$ \\
\hline & & $\begin{array}{l}\text { Doxiciclina, } 200 \mathrm{mg} \text { una sola dosis ó } 100 \mathrm{mg} \text { cada } \\
12 \mathrm{~h} \text { por } 5 \text { días. }\end{array}$ \\
\hline & & $\begin{array}{l}\text { Josamicina, dos dosis orales de } 1 \mathrm{~g} \text { cada } 8 \mathrm{~h} \text { por } 5 \\
\text { días. }\end{array}$ \\
\hline & & Ciprofloxacina, $750 \mathrm{mg}$ cada $12 \mathrm{~h}$ por 7 días. \\
\hline & \multirow{4}{*}{ Niños } & $\begin{array}{l}\text { Doxiciclina, } 2.2 \mathrm{mg} / \mathrm{kg} \text { cada } 12 \mathrm{~h} \text { para niños con } \\
\text { peso }<45 \mathrm{~kg} \text { ó }>45 \text { por } 5-10 \text { días. }\end{array}$ \\
\hline & & Claritromicina, $7.5 / \mathrm{mg} / \mathrm{kg} / \mathrm{hora}$ por 7 días. \\
\hline & & Azitromicina, $10 \mathrm{mg} / \mathrm{kg} /$ día por 3 días. \\
\hline & & Josamicina, $50 \mathrm{mg} / \mathrm{kg}$ cada $12 \mathrm{~h}$ por 5 días. \\
\hline & Mujeres embarazadas & Josamicina, $50 \mathrm{mg} / \mathrm{kg}$ cada $12 \mathrm{~h}$ por 5 días \\
\hline \multirow{4}{*}{$\begin{array}{l}\text { Fiebre manchada de las Montañas } \\
\text { Rocosas }\end{array}$} & Adultos & Doxiciclina, $100 \mathrm{mg}$ cada $12 \mathrm{~h}$ por 5 - 10 días. \\
\hline & \multirow{2}{*}{ Niños } & $\begin{array}{l}\text { Doxiciclina, } 2.2 \mathrm{mg} / \mathrm{kg} \text { cada } 12 \mathrm{~h} \text { para niños con } \\
\text { peso }<45 \mathrm{~kg} \text { ó }>45 \text { por } 5-10 \text { días. }\end{array}$ \\
\hline & & $\begin{array}{l}\text { Cloramfenicol, } 12.5 \text { - } 25 \mathrm{mg} / \mathrm{kg} \text { cada } 6 \mathrm{~h} \text { por } 5 \text { - } 10 \\
\text { días. }\end{array}$ \\
\hline & Mujeres embarazadas & Doxiciclina, $100 \mathrm{mg}$ cada $12 \mathrm{~h}$ por 5 - 10 días. \\
\hline
\end{tabular}

Adaptado de Parola et al (48).

en mujeres gestantes y en neonatos y niños menores a los 8 años. En algunos países como los Estados Unidos el uso de la Josamicina ha sido controvertido debido a los pocos estudios que se han llevado a cabo en este país (48).

Además, de los antibióticos mencionados también se ha estudiado el uso como tratamiento alternativo, de algunas quinolonas como la Fluoroquinolona, pero los resultados indican que se debe continuar con más estudios que soporten el uso de este antibiótico. El uso de gran cantidad de antibióticos de amplio espectro como las Cefalosporinas y los Aminoglicosidos han sido ineficaces en el tratamiento contra la Rickettsiosis (48).

\section{Prevención y control}

Según el CDC, disminuir la exposición a los ectoparásitos vectores, es la manera más eficaz de reducir el riesgo de la infección por rickettsias patógenas. A continuación se presentan algunos métodos para disminuir la infestación de los vectores en personas que se mantienen permanentemente expuestas a ellos:

- Usar ropa de colores claros que permite ver los ectoparásitos que se posan sobre la misma.
- Meter las botas de los pantalones dentro de la medias para que los ectoparásitos no puedan entrar en el interior del pantalón y tener contacto con las piernas.

- Aplicar repelentes en la ropa que contengan permetrina además de repelentes en la piel que contengan DEET (N, N-dietil-m-toluamida). Hay que tener precaución con la aplicación de estos repelentes en los niños, debido a que se ha asociado con reacciones adversas.

- Llevar un monitoreo permanente y minucioso de su cuerpo luego de regresar de las áreas que están potencialmente infestadas de ectoparásitos. Si es posible utilizar un espejo de cuerpo entero para ver todas las partes del cuerpo y retirar todos los ectoparásitos que se encuentren.

- Examinar los niños por todo el cuerpo sobre todo en la áreas donde se mimetizan mejor los ectoparásitos como en la cabeza, la zona inguinal y la axilas. También es importante revisar los animales domésticos luego de haber regresado al peri-domicilio de las zonas probablemente infestadas por ectoparásitos (123).

Hay que tener en cuenta que si la infestación es por garrapatas, estas se deben retirar del cuerpo de acuerdo a las siguientes especificaciones: 
- Utilizar pinzas de punta fina y proteger los dedos con un papel desechable, una toalla de papel o guantes de látex. Se debe evitar a toda costa eliminar las garrapatas con las manos desnudas.

- Agarrar la garrapata tan cerca de la superficie de la piel como sea posible y tirar hacia arriba con presión constante y uniforme. No doblar o arrancar la garrapata, esto puede hacer que su aparato bucal permanezca dentro de la piel (si esto sucede, se deben retirar las piezas bucales remanentes con pinzas).

- Después de retirar la garrapata, desinfectar bien el sitio de la mordedura y lavarse las manos con agua y jabón (123).

\section{Conclusiones y preguntas de investigación}

En adición a la re-emergencia planteada para algunas de las especies de Rickettsia ya conocidas y previamente detectadas en nuestro medio, vale la pena también destacar la posibilidad de que especies previamente consideradas no patógenas, tales como la Rickettsia felis o $R$. parkeri $(86,124,125)$, puedan representar formas emergentes de agentes potencialmente patógenos para el hombre y los animales en nuestro medio. En el mismo orden de ideas, en los últimos años, múltiples casos de BSF han sido confirmados a través de IFI, en el sureste de ese país, y recientemente se han reportado casos asociados con pulgas de gatos (Ctenocephalides felis), que transmiten la Rickettsia felis, diagnosticados por PCR $(86,126,127)$. Recientemente en el estado de Yucatán, México, se diagnosticaron casos clínicos en humanos de Rickettsialpox (Rickettsia akari) (128) y de casos severos de infección por Rickettsia felis la cual se asoció con hepatitis (129), estos casos refuerzan la importancia de estas especies como potenciales patógenos que pueden causar graves enfermedades en los humanos.

Estos reportes establecen por un lado, la posibilidad real de que puedan presentarse nuevos brotes de ricketsiosis en las mismas zonas previamente estudiadas o en otras en las que desconocemos su presencia (86) y de otro demuestran la carencia de información sobre la real situación de la enfermedad, factores de riesgo, vectores y reservorios asociados con la presencia de la infección en dichas zonas. Así mismo no se cuenta con pruebas diagnósticas de fase aguda "para todas las especies" que ayuden a la detección oportuna del problema para instaurar medidas de intervención que controlen la letalidad de la enfermedad.
Esta revisión es solo un vistazo general del tema para estimular la curiosidad de los investigadores y personal de salud, a continuar trabajando en la solución de preguntas fundamentales acerca de las rickettsiosis, generalmente sub-diagnósticadas y subestimadas en el contexto latinoamericano, cuando en realidad se trata de enfermedades importantes que afectan individuos inmunocompetentes de todas las edades, y conducen frecuentemente a la muerte. El control efectivo de la rickettsiosis y de sus vectores, requerirá de un entendimiento comprensivo de la ecología de las enfermedades. En éste sentido, algunos de los cuestionamientos más importantes que aún esperan ser despejados para nuestro país (y algunos casos para el mundo), son entre otros: qué causa que las epidemias ocurran en algunas áreas y como las rickettsias persisten en los periodos entre epidemias?, cuál es la dinámica de la transmisión enzoótica de la infección? cuál es la importancia de los varios tipos de garrapatas y otros vectores involucrados en su transmisión (pulgas y piojos), y las especies de hospederos y como se ven ellos a su vez afectados por el clima y las variaciones de hábitat sobre la diseminación y el control de la infección?, cuáles son las interrelaciones entre las garrapatas infectadas, los reservorios vertebrados y la agricultura?, cuáles son las relaciones entre los cambios medioambientales y las dinámicas de las rickettsias en los vectores y sus hospederos vertebrados?, que papel juegan los animales domésticos y peridomésticos como posibles reservorios?, cuáles son las especies de garrapatas incriminadas y la caracterización de su densidad, competencia vectorial y preferencia de hospederos en hábitats heterogéneos?, y finalmente, qué otras rickettsias del SFG o del TG que causan enfermedades clínicas humanas podrían estar presentes en nuestra geografía. Solo a través del estudio multidisciplinario (ecológico, médico, entomológico, antropológico, entre otros.) de los factores que afectan éste complejo panorama, se podrá en un futuro dar respuesta real a todos estos cuestionamientos.

\section{Financiación}

Proyecto 2387 de la Fundación para la Promoción de la Investigación y la Tecnología del Banco de la República. Agradecimientos a la estrategia de sostenibilidad 2009-2010 de la Vicerrectoría de investigación de la Universidad de Antioquia, por su apoyo económico.

\section{Conflicto de intereses}

Los autores arriba suscritos declaramos que no existe ningún conflicto de interés relacionado con la publicación de éste manuscrito. 


\section{Referencias}

1. Brenner DJ, Krieg NR, Staley JT, Bergey's. Manual of Systematic Bacteriology second edition; Athens, GA. 2005, 96 pp.

2. Gillespie JJ, Williams K, Shukla M, Snyder EE, Nordberg EK, Ceraul SM, Dharmanolla C, Rainey D, Soneja J, Shallom JM, Vishnubhat ND, Wattam R, Purkayastha A, Czar M, Crasta O, Setubal JC, Azad AF, Sobral BS. Rickettsia phylogenomics: unwinding the intricacies of obligate intracellular life. PloS one 2008;3(4): e2018.

3. Labruna MB. Ecology of rickettsia in South America. Annals of the New York Academy of Science 2009;1166:156-166

4. Mostorino RE. Identificación de una nueva área de infección por rickettsias del grupo typhi: estudio de un brote de tifus en Huánuco. Revista Peruana de Medicina Experimental y Salud Publica 2003;20:15-21

5. Olano JP, Ramírez G, Moscoso B. Epidemic typhus outbreaks in Cuzco, Peru. American Journal of Tropical Medicine and Hygiene 1997;60:282

6. Pacheco O, Giraldo R, Martinez M, Hidalgo M, Galeano A, Echeverri I, Echevarria L, Parra E, Rey G. Estudio de brote febril hemorrágico en el corregimiento de Alto de Mulatos - Distrito Especial Portuario de Turbo, Antioquia, enero de 2008. Informe Quincenal Epidemiológico Nacional 2008;13:145-160

7. Patino L, Afanador A, Paul JH. A spotted fever in Tobia, Colombia. 1937. Biomedica 2006;26(2):178-193

8. Acosta J, Díaz A, Urquijo L, Rey G, Sepúlveda C, Herrera D, Zuluaga W. Brote de Rickettsia rickettsii en Necoclí, Antioquia, Colombia, 2006. Informe Quincenal Epidemiológico Nacional 2006;11:161-176

9. Hidalgo M, Miranda J, Heredia D, Zambrano P, Vesga JF, Lizarazo D, Mattar S, Valbuena G. Outbreak of Rocky Mountain spotted fever in Cordoba, Colombia. Memórias do Instituto Oswaldo Cruz 2011;106(1):117-118

10. Telford SR GH. Emerging tick-borne infections: rediscovered and better characterized, or truly 'new'?. Parasitology 2004;129:301- 327

11. Wilson LB, Chowning WM. Studies in Pyroplasmosis hominis ("spotted fever" or "tick fever" of the Rocky Mountains). Journal of Infectious Diseases 1904;1:31-57

12. Ormsbee RA. A review: "Studies in Pyroplasmosis hominis ('spotted fever' or 'tick fever' of the Rocky Mountains)" by Louis B. Wilson and William M. Chowning, published in The Journal of Infectious Diseases 1:31-57, 1904. Reviews of Infectious Disiases 1979;1(3):559-562

13. Heyneman D. The blight of the Bitterroot, the mysterious Rocky Mountain spotted fever, and the significant role of Wilson and Chowning--a commentary. Wilderness and Environmental Medicine 2001;12(2):118-120
14. Ricketts H. Asummary of investigations of the nature and means of transmission of Rocky Mountain spotted fever. Contributions to Medical Science by Howard Taylor Ricketts, 1870-1910. Chicago: University of Chicago Press; 1911:278-372

15. Ricketts H. A micro-organism, which apparently has a specific relationship to Rocky Mountain spotted fever. Journal of the American Medical Association 1909;52:379-380

16. LaBier CR. Rocky Mountain spotted fever in Indiana. Journal of the Indiana State Medical Association 1925;18:418-419

17. Parker RR. Certain phases of the problem of Rocky Mountain spotted fever: a summary. Archives of Pathology 1933;15:398-429

18. Badger LF, Dyer RE, Rumreich A. An infection of the Rocky Mountain type: identification in the eastern part of the United States. Public Health Reports 1931;46:463-470

19. Rumreich A, Dyer RE, Badger LF. The typhus-Rocky Mountain spotted fever group: an epidemiological and clinical study in the eastern and southeastern states. Public Health Reports 1931;46:470-480

20. Piza J, Salles-Gomes L, Meyer J, Fleury JP, Castro O, Rodrigues C, Rocha Lima H. Le typhus exanthematique a São Paulo. Comptes Rendus des Seances de la Societe de Biologie et de ses Filiales 1931;106:1020-1022

21. Parker RR, Davis GE. Protective value of convalescent sera of São Paulo exanthematic typhus against the virus of Rocky Mountain spotted fever. Public Health Reports 1933;48:501-507

22. Raoult D, Parola P. Rickettsial diseases New York, London; 2008; 37-38,51,97-98

23. Kligler IJ, Comaroff R. An epidemic outbreak of murine typhus in a labour group in an inland village in Palestine. Transactions of the Royal Society of Tropical Medicine and Hygiene 1936;30:363-368

24. Neill MH. A Description of a Scrotal Lesion in Guinea pigs Infected with Mexican Typhus. Public Health Reports 1917;33:1105

25. Mooser H. An American type of typhus. Transactions of the Royal Society of Tropical Medicine and Hygiene 1928;22:175-176

26. Reitler R, Btesh S, Marberg K. Endemic typhus in Palestine. Transactions of the Royal Society of Tropical Medicine and Hygiene 1939;33:197-212

27. Mooser $\mathrm{H}$. Experiments relating to pathology and etiology of Mexican typhus (Tabardillo): clinical course and pathologic anatomy of Tabardillo in guinea pigs. Journal of Infectious Diseases 1928;43:241-260

28. Maxcy KF. An epidemiological study of endemic typhus (Brill's disease) in the southeastern United States. Public Health Reports 1926;41:2967-2995 
29. Mooser H, Castaneda MR, Zinsser H. Mexican typhus from rat to rat by polyplax spinulosus. Journal of Experimetnal Medicine 1931;54:567-575

30. Lépine P. Sur la présence dans l'encéphale des rat captures à Athenes d'un virus revêtant les caractères expérimentaux du typhus exanthématique (virus mexicain). Comptes Rendus de l Academie des Sciences 1932;194:401-403

31. Lorandos N. Cases of endemic typhus (Brill's disease) in Athens. Medical Athens 1934;42:639-641

32. Baxter JD. The typhus group. Clinics in Dermatology 1996;14(3):271-278

33. Dumler JS, Taylor JP, Walker DH. Clinical and laboratory features of murine typhus in south Texas, 1980 through 1987. Jama 1991;266(10):1365-1370

34. Gikas A, Doukakis S, Pediaditis J, Kastanakis S, Psaroulaki A, Tselentis Y. Murine typhus in Greece: epidemiological, clinical, and therapeutic data from 83 cases. Transactions of the Royal Society of Tropical Medicine and Hygiene 2002;96(3):250-253

35. Zinsser H. Rats, Lice, and History Londres: Broadway House; 1935:1-301

36. Raoult D, Dutour O, Houhamdi L, Jankauskas R, Fournier PE, Ardagna Y, Drancourt M, Signoli M, La VD, Macia Y, Aboudharam G. Evidence for louse-transmitted diseases in soldiers of Napoleon's Grand Army in Vilnius. Journal of Infectious Diseases 2006;193(1):112-120

37. Patterson KD. Typhus and its control in Russia, 18701940. Medical History 1993;37(4):361-381

38. Walker DH. Biology of Rickettsial Diseases. CRC Press 1st ed. ed Boca Raton, FL; 1988

39. Nicolle $\mathrm{C}$, Comte $\mathrm{C}$, Conseil E. Transmission expérimentale du typhus exanthématique par le pou de corps. Comptes Rendus de l Academie des Sciences 1909;149:486-489

40. Gross L. How Charles Nicolle of the Pasteur Institute discovered that epidemic typhus is transmitted by lice: reminiscences from my years at the Pasteur Institute in Paris. Proceedings of the National Academy of Sciences of the United States of America 1996;93:10539-10540

41. Andersson JO, Andersson SG. A century of typhus, lice and Rickettsia. Research in Microbiology 2000;151(2):143-150

42. Raoult D, Ndihokubwayo JB, Tissot-Dupont H, Roux V, Faugere B, Abegbinni R, Birtles RJ. Outbreak of epidemic typhus associated with trench fever in Burundi. Lancet 1998;352(9125):353-358

43. Tarasevich I, Rydkina E, Raoult D. Outbreak of epidemic typhus in Russia. Lancet 1998;352(9134):1151

44. Raoult D, Birtles RJ, Montoya M, Perez E, Tissot-Dupont H, Roux V, Guerra H. Survey of three bacterial louseassociated diseases among rural Andean communities in Peru: prevalence of epidemic typhus, trench fever, and relapsing fever. Clinical Infectious Diseases 1999;29(2):434-436
45. Mokrani K, Fournier PE, Dalichaouche M, Tebbal S, Aouati A, Raoult D. Reemerging threat of epidemic typhus in Algeria. Journal of Clinical Microbiology 2004;42(8):3898-3900

46. Niang M, Brouqui P, Raoult D. Epidemic typhus imported from Algeria. Emerging Infectious Dieseases 1999;5(5):716-718

47. Brouqui P, Stein A, Dupont HT, Gallian P, Badiaga S, Rolain JM, Mege JL, La Scola B, Berbis P, Raoult D. Ectoparasitism and vector-borne diseases in 930 homeless people from Marseilles. Medicine (Baltimore) 2005;84(1):61-68

48. Parola P, Paddock CD, Raoult D. Tick-borne rickettsioses around the world: emerging diseases challenging old concepts. Clinical Microbiology Reviews 2005;18(4):719-756

49. Murria PR, Baron EJ, Jorgensen JH. Manual of clinical microbiology eighth edition. In: Murray EicPR, ed; 2003:1005-1013pp

50. Perlman SJ, Hunter MS, Zchori-Fein E. The emerging diversity of Rickettsia. Proceedings of the Royal Society - Biological Sciences 2006;273(1598):2097-2106

51. Parola P, Raoult D. Ticks and tickborne bacterial diseases in humans: an emerging infectious threat. Clinical Infectious Diseases 2001;32(6):897-928

52. Weisburg WG, Dobson ME, Samuel JE, Dasch GA, Mallavia LP, Baca O, Mandelco L, Sechrest JE, Weiss E, Woese CR. Phylogenetic diversity of the Rickettsiae. Journal of Bacteriology 1989;171(8):4202-4206

53. Roux V, Bergoin M, Lamaze N, Raoult D. Reassessment of the taxonomic position of Rickettsiella grylli. International Journal of Systematic Bacteriology 1997;47:1255-1257

54. Neimark H, Johansson KE, Rikihisa Y, Tully JG. Proposal to transfer some members of the genera Haemobartonella and Eperythrozoon to the genus Mycoplasma with descriptions of 'Candidatus Mycoplasma haemofelis', 'Candidatus Mycoplasma haemomuris', 'Candidatus Mycoplasma haemosuis' and 'Candidatus Mycoplasma wenyonii'. International Journal of Systematic and Evolutionary Microbiology 2001;51:891-899

55. Azad AF, Beard CB. Rickettsial pathogens and their arthropod vectors. Emerging Infectious Dieseases 1998;4(2):179-186

56. McElroy KM, Blagburn BL, Breitschwerdt EB, Mead PS, McQuiston JH. Flea-associated zoonotic diseases of cats in the USA: bartonellosis, flea-borne rickettsioses, and plague. Trends in Parasitology 2010;26(4):197-204

57. Martinez J SS, Veiga E, Matsuyama S, Cossart P. Ku70, a Component of DNA-Dependent Protein Kinase, Is a Mammalian Receptor for Rickettsia conorii. Cell 2005;123:1013-1023

58. Valbuena G, Feng HM, Walker DH. Mechanisms of immunity against rickettsiae. New perspectives and 
opportunities offered by unusual intracellular parasites. Microbes and Infection 2002;4(6):625-633

59. Balraj P, Renesto P, Raoult D. Advances in rickettsia pathogenicity. Annals of the New York Academy of Science 2009;1166:94-105

60. Walker DH, Valbuena GA, Olano JP. Pathogenic mechanisms of diseases caused by Rickettsia. Annals of the New York Academy of Science 2003;990:1-11

61. Van Kirk LS, Hayes SF, Heinzen RA. Ultrastructure of Rickettsia rickettsii actin tails and localization of cytoskeletal proteins. Infection and Immunity 2000;68(8):4706-4713

62. Mantovani A, Garlanda C, Introna M, Vecchi A. Regulation of endothelial cell function by pro- and anti-inflammatory cytokines. Transplantation Proceedings 1998;30(8):42394243

63. Walker DH, Popov VL, Crocquet-Valdes PA, Welsh CJ, Feng HM. Cytokine-induced, nitric oxide-dependent, intracellular antirickettsial activity of mouse endothelial cells. Laboratory Investigation 1997;76(1):129-138

64. Feng H, Popov VL, Yuoh G, Walker DH. Role of T lymphocyte subsets in immunity to spotted fever group Rickettsiae. Journal of Immunology 1997;158(11):5314-5320

65. Milano S, D’Agostino P, Di Bella G, La Rosa M, Barbera C, Ferlazzo V, Mansueto P, Rini GB, Barera A, Vitale G, Mansueto S, Cillari E. Interleukin-12 in human boutonneuse fever caused by Rickettsia conorii. Scandinavian Journal of Immunology 2000;52(1):91-95

66. Billings AN, Feng HM, Olano JP, Walker DH. Rickettsial infection in murine models activates an early antirickettsial effect mediated by NK cells and associated with production of gamma interferon. American Journal of Tropical Medicine and Hygiene 2001;65(1):52-56

67. Masters EJ, Olson GS, Weiner SJ, Paddock CD. Rocky Mountain spotted fever: a clinician's dilemma. Archives of Internal Medicine 2003;163(7):769-774

68. Piranda EM, Faccini JL, Pinter A, Saito TB, Pacheco RC, Hagiwara MK, Labruna MB. Experimental infection of dogs with a Brazilian strain of Rickettsia rickettsii: clinical and laboratory findings. Memórias do Instituto Oswaldo Cruz 2008;103(7):696-701

69. Saito TB, Cunha-Filho NA, Pacheco RC, Ferreira F, Pappen FG, Farias NA, Larsson CE, Labruna MB. Canine infection by rickettsiae and ehrlichiae in southern Brazil. American Journal of Tropical Medicine and Hygiene 2008;79(1):102-108

70. Scorpio DG, Wachtman LM, Tunin RS, Barat NC, Garyu JW, Dumler JS. Retrospective clinical and molecular analysis of conditioned laboratory dogs (Canis familiaris) with serologic reactions to Ehrlichia canis, Borrelia burgdorferi, and Rickettsia rickettsii. Journal of American Association for Laboratory Animal Science 2008;47(5):23-28

71. Paddock CD, Brenner O, Vaid C, Boyd DB, Berg JM, Joseph RJ, Zaki SR, Childs JE. Short report: concurrent Rocky Mountain spotted fever in a dog and its owner. American Journal of Tropical Medicine and Hygiene 2002;66(2):197-199

72. López J AK, Azócar T. Evidencia clínica y serológica de rickettsiosis canina en Chile. Revista Chilena de Infectología 2007;24(3):189-193

73. Hidalgo M, Vesga JF, Lizarazo D, Valbuena G. A survey of antibodies against Rickettsia rickettsii and Ehrlichia chafeensis in domestic animals from a rural area of Colombia. American Journal of Tropical Medicine and Hygiene 2009;80(6):1029-1030

74. Elchos BN, Goddard J. Implications of presumptive fatal Rocky Mountain spotted fever in two dogs and their owner. Journal of the American Veterinary Medical Association 2003;223(10):1450-1452

75. Bayliss DB, Morris AK, Horta MC, Labruna MB, Radecki SV, Hawley JR, Brewer MM, Lappin MR. Prevalence of Rickettsia species antibodies and Rickettsia species DNA in the blood of cats with and without fever. Journal of Feline Medicine and Surgery 2009;11(4):266-270

76. Case JB, Chomel B, Nicholson W, Foley JE. Serological survey of vector-borne zoonotic pathogens in pet cats and cats from animal shelters and feral colonies. Journal of Feline Medicine and Surgery 2006;8(2):111-117

77. Horta MC, Moraes-Filho J, Casagrande RA, Saito TB, Rosa SC, Ogrzewalska M, Matushima ER, Labruna MB. Experimental Infection of Opossums Didelphis aurita by Rickettsia rickettsii and Evaluation of the Transmission of the Infection to Ticks Amblyomma cajennense. Vector Borne and Zoonotic Disease 2009;9(1):109-118

78. Souza CE, Moraes-Filho J, Ogrzewalska M, Uchoa FC, Horta MC, Souza SS, Borba RC, Labruna MB. Experimental infection of capybaras Hydrochoerus hydrochaeris by Rickettsia rickettsii and evaluation of the transmission of the infection to ticks Amblyomma cajennense. Veterinary Parasitology 2009;161(1-2):116-121

79. Bischof R, Rogers DG. Serologic survey of select infectious diseases in coyotes and raccoons in Nebraska. Journal of Wildlife Disease 2005;41(4):787-791

80. Ocaranza F. Historia de la medicina en México, "Las grandes epidemias del siglo XVI" México; 1995

81. Schriefer ME, Sacci JB, Jr., Dumler JS, Bullen MG, Azad AF. Identification of a novel rickettsial infection in a patient diagnosed with murine typhus. Journal of Clinical Microbiology 1994;32(4):949-954

82. Medina-Sanchez A, Bouyer DH, Alcantara-Rodriguez V, Mafra C, Zavala-Castro J, Whitworth T, Popov VL, 
Fernandez-Salas I, Walker DH. Detection of a typhus group Rickettsia in Amblyomma ticks in the state of Nuevo Leon, Mexico. Annals of the New York Academy of Science 2005;1063:327-332

83. Galvao MA. Rickettsiosis of the Genus Rickettssia in South America. Annals of the New York Academy of Science 2003;990:57-61

84. Dias E, Martins A. Spotted fever in Brazil. American Journal of Tropical Medicine and Hygiene 1939;19:103-108

85. Conti-Diaz IA, Rubio I, Somma Moreira RE, Perez Bormida G. Lymphatic cutaneous rickettsiosis caused by Rickettsia conorii in Uruguay. Revista do Instituto de Medicina Tropical de Sao Paulo 1990;32(5):313-318

86. Hidalgo M, Sanchez R, Orejuela L, Hernandez J, Walker DH, Valbuena G. Prevalence of antibodies against spotted fever group rickettsiae in a rural area of Colombia. American Journal of Tropical Medicine and Hygiene 2007;77(2):378-380

87. Ripoll CM, Remondegui CE, Ordonez G, Arazamendi R, Fusaro H, Hyman MJ, Paddock CD, Zaki SR, Olson JG, Santos-Buch CA. Evidence of rickettsial spotted fever and ehrlichial infections in a subtropical territory of Jujuy, Argentina. American Journal of Tropical Medicine and Hygiene 1999;61(2):350-354

88. Guedes E, Leite RC, Prata MC, Pacheco RC, Walker DH, Labruna MB. Detection of Rickettsia rickettsii in the tick Amblyomma cajennense in a new Brazilian spotted feverendemic area in the state of Minas Gerais. Memórias do Instituto Oswaldo Cruz 2005;100(8):841-845

89. Labruna MB, Camargo LM, Camargo EP, Walker DH. Detection of a spotted fever group Rickettsia in the tick Haemaphysalis juxtakochi in Rondonia, Brazil. Veterinary Parasitology 2005;127(2):169-174

90. Pacheco RC, Moraes-Filho J, Nava S, Brandao PE, Richtzenhain LJ, Labruna MB. Detection of a novel spotted fever group rickettsia in Amblyomma parvum ticks (Acari: Ixodidae) from Argentina. Experimental and Applied Acarology 2007;43(1):63-71

91. Stevenson HL, Labruna MB, Montenieri JA, Kosoy MY, Gage KL, Walker DH. Detection of Rickettsia felis in a New World flea species, Anomiopsyllus nudata (Siphonaptera: Ctenophthalmidae). Journal of Medical Entomology 2005;42(2):163-167

92. Labruna MB, Pacheco RC, Nava S, Brandao PE, Richtzenhain LJ, Guglielmone AA. Infection by Rickettsia bellii and Candidatus "Rickettsia amblyommii" in Amblyomma neumanni ticks from Argentina. Microbial Ecology 2007;54(1):126-133

93. Pinter A, Labruna MB. Isolation of Rickettsia rickettsii and Rickettsia bellii in cell culture from the tick Amblyomma aureolatum in Brazil. Annals of the New York Academy of Science 2006;1078:523-529

94. Abbot P, Aviles AE, Eller L, Durden LA. Mixed infections, cryptic diversity, and vector-borne pathogens: evidence from Polygenis fleas and Bartonella species. Applied and Environmental Microbiology 2007;73(19):6045-6052

95. Labruna MB, McBride JW, Bouyer DH, Camargo LM, Camargo EP, Walker DH. Molecular evidence for a spotted fever group Rickettsia species in the tick Amblyomma longirostre in Brazil. Journal of Medical Entomology 2004;41(3):533-537

96. Horta MC, Pinter A, Schumaker TT, Labruna MB. Natural infection, transovarial transmission, and transstadial survival of Rickettsia bellii in the Tick Ixodes loricatus (Acari: Ixodidae) from Brazil. Annals of the New York Academy of Science 2006;1078:285-290

97. Labruna MB, Whitworth T, Bouyer DH, McBride J, Camargo LM, Camargo EP, Popov V, Walker DH. Rickettsia bellii and Rickettsia amblyommii in Amblyomma ticks from the State of Rondonia, Western Amazon, Brazil. Journal of Medical Entomology 2004;41(6):1073-1081

98. Labruna MB, Whitworth T, Horta MC, Bouyer DH, McBride JW, Pinter A, Popov V, Gennari SM, Walker DH. Rickettsia species infecting Amblyomma cooperi ticks from an area in the state of Sao Paulo, Brazil, where Brazilian spotted fever is endemic. Journal of Clinical Microbiology 2004;42(1):90-98

99. Labruna MB, Leite RC, Faccini JL, Ferreira F. Life cycle of the tick Haemaphysalis leporis-palustris (Acari: Ixodidae) under laboratory conditions. Experimental and Applied Acarology 2000;24(9):683-694

100. Hidalgo M, Salguero E, de la Ossa A, Sanchez R, Vesga JF, Orejuela L, Valbuena G. Murine typhus in Caldas, Colombia. American Journal of Tropical Medicine and Hygiene 2008;78(2):321-322

101. Walker DH. The realities of biodefense vaccines against Rickettsia. Vaccine 2009;27 Suppl 4:D52-55

102. Harris S. Japanese biological warfare research on humans: a case study of microbiology and ethics. Annals of the New York Academy of Science 1992;666:21-52

103. Spencer RR PR. Rocky Mountain spotted fever: vaccination of monkeys and man. Public Health Reports 1925;40:2159 $-2167$

104. DuPont HL, Hornick RB, Dawkins AT, Heiner GG, Fabrikant IB, Wisseman CL, et al. Rocky Mountain spotted fever: a comparative study of the active immunity induced by inactivated and viable pathogenic Rickettsia rickettsii. Journal of Infectious Diseases 1973;128(3):340-344 
105. Kenyon RH, Sammons LS, Pedersen CE. Comparison of three rocky mountain spotted fever vaccines. Journal of Clinical Microbiology 1975;2(4):300-304

106. Clements ML, Wisseman CL, Woodward TE, Fiset P, Dumler JS, McNamee W, Black RE, Rooney J, Hughes TP, Levine MM. Reactogenicity, immunogenicity, and efficacy of a chick embryo cell-derived vaccine for Rocky Mountain spotted fever. Journal of Infectious Diseases 1983;148(5):922-930

107. Anacker RL, List RH, Mann RE, Hayes SF, Thomas LA. Characterization of monoclonal antibodies protecting mice against Rickettsia rickettsii. Journal of Infectious Diseases 1985;151(6):1052-1060

108. Li H, Lenz B, Walker DH. Protective monoclonal antibodies recognize heat-labile epitopes on surface proteins of spotted fever group rickettsiae. Infection and Immunity 1988;56(10):2587-2593

109. Feng HM, Whitworth T, Olano JP, Popov VL, Walker DH. Fc-dependent polyclonal antibodies and antibodies to outer membrane proteins A and B, but not to lipopolysaccharide, protect SCID mice against fatal Rickettsia conorii infection. Infection and Immunity 2004;72(4):2222-2228

110. Feng HM, Walker DH, Wang JG. Analysis of T-celldependent and -independent antigens of Rickettsia conorii with monoclonal antibodies. Infection and Immunity 1987;55(1):7-15

111. Feng HM, Walker DH. Cross-protection between distantly related spotted fever group rickettsiae. Vaccine 2003;21(2526):3901-3905

112. Valbuena G, Jordan JM, Walker DH. T cells mediate cross-protective immunity between spotted fever group rickettsiae and typhus group rickettsiae. Journal of Infectious Diseases 2004;190(7):1221-1227

113. Walker DH, Hudnall MS, Szaniawski WK, Feng HM. Monoclonal antibody-based immunohistochemical diagnosis of rickettsialpox: The macrophage is the principal target. Modern Pathology 1999;12:529-533

114. Walker DH, Parks FM, Betz TG, Taylor JP, Muehlberger JW. Histopathology and immunohistologic demonstration of the distribution of Rickettsia typhi in fatal murine typhus. American Journal of Clinical Pathology 1989;91(6):720-724

115. Cardeñosa N, Sanfeliu, I, Segura, F. Diagnóstico microbiológico de las rickettsiosis. Enfermedades Infecciosas y Microbiología Clínica 1997;15:32-37

116. Murria P, Baron E, Jorgensen J. Manual of clinical microbiology eighth edition. In: Murray EicPR, ed; 2003:1005-1013pp

117. Freitas LH, Faccini JL, Labruna MB. Experimental infection of the rabbit tick, Haemaphysalis leporispalustris, with the bacterium Rickettsia rickettsii, and comparative biology of infected and uninfected tick lineages. Experimental and Applied Acarology 2009;47(4):321-345

118. Oteo JA, Portillo A, Santibanez S, Blanco JR, Perez-Martinez L, Ibarra V. Cluster of cases of human Rickettsia felis infection from Southern Europe (Spain) diagnosed by PCR. Journal of Clinical Microbiology 2006;44(7):2669-2671

119. Webb L CM, Malloy DC, Dasch GA, Azad AF. Detection of Murine Typhus Infection in Fleas by Using the Polymerase Chain Reaction. Journal of Clinical Microbiology 1990; 28 (3):530-534

120. Roux V RE, Eremeeva M, Raoult D. Citrate synthase gene comparison, a new tool for phylogenetic analysis, and its application for the rickettsiae. International Journal of Systematic Bacteriology 1997;47:252-261

121. Roux V RD. Phylogenetic analysis of members of the genus Rickettsia using the gene encoding the outermembrane protein $\mathrm{OOmpB}$ (ompB). International Journal of Systematic Bacteriology 2000;50:1449-1455

122. Svendsen CB, Boye M, Struve C, Krogfelt KA. A novel fluorescent in situ hybridization technique for detection of Rickettsia spp. in archival samples. Journal of Microbiological Methods 2009;76(3):301-304

123. (CDC). DohahsCfDCaP. Rock Mountain Spotted Fever. Vol. Page last reviewed: November 4, 2010. Atlanta; 2011

124. Pacheco RC, Venzal JM, Richtzenhain LJ, Labruna MB. Rickettsia parkeri in Uruguay. Emerging Infectious Dieseases 2006;12(11):1804-1805

125. Silveira I, Pacheco RC, Szabo MP, Ramos HG, Labruna MB. Rickettsia parkeri in Brazil. Emerging Infectious Dieseases 2007;13(7):1111-1113

126. Higgins J, Radulovic, S, Schriefer, M, Azad, A. Rickettsia felis: a New Species of Pathogenic Rickettsia Isolated from Cat Fleas. Journal of Clinical Microbiology 1996;34 (3):671-674

127. Horta MC, Chiebao DP, de Souza DB, Ferreira F, Pinheiro SR, Labruna MB, Schumaker TT. Prevalence of Rickettsia felis in the fleas Ctenocephalides felis felis and Ctenocephalides canis from two Indian villages in Sao Paulo Municipality, Brazil. Annals of the New York Academy of Science 2006;1078:361-363

128. Zavala-Castro JE, Zavala-Velazquez JE, Peniche-Lara GF, Sulu Uicab JE. Human rickettsialpox, southeastern Mexico. Emerging Infectious Dieseases 2009;15(10):1665-1667

129. Zavala-Castro J, Zavala-Velazquez J, Walker D, PerezOsorio J, Peniche-Lara G. Severe human infection with Rickettsia felis associated with hepatitis in Yucatan, Mexico. International Journal of Medical Microbiology 2009;299(7):529-533 